\title{
Estereótipos sociais na voz das crianças: uma análise de livros escolares do Ensino Básico português
}

Teresa da Conceição Mendes de Castro ${ }^{1}$ Rui Manuel do Nascimento Lima Ramos ${ }^{1}$

\section{Resumo}

0 presente estudo inscreve-se no domínio abrangente dos Estudos da Criança e analisa um conjunto de textos de manuais/livros escolares usados no sistema de ensino português ( $4^{\circ}$ ano de escolaridade, do Ensino Básico), pretendendo revelar as representações que estes constroem das crianças e da infância, através dos mecanismos de atribuição de voz às crianças, bem como a forma como essas representações são apresentadas às crianças-leitoras, influenciando seus modos de ser, pensar e agir. Para o efeito, confere especial relevo à materialidade linguística e às questões enunciativas, no quadro específico da análise do discurso, recebendo também contributos das teorias da enunciação, da análise textual, da pragmática, do interacionismo sociodiscursivo e, como não podia deixar de ser, num estudo ligado às crianças, da sociologia da infância. Conclui que as crianças representadas nos textos são indivíduos desprovidos de voz e de poder: consumidores, mas não coprodutores de cultura. As crianças-personagens surgem submissas aos poderes instituídos e quase nunca apresentam a sua opinião sobre os assuntos que lhes dizem respeito. Limitam-se a seguir as regras e a obedecer a quem tem o poder de exercer a autoridade e os castigos. Os textos surgem configurados dominantemente como de conformação e não de questionamento.

\section{Palavras-chave}

Análise do discurso - Criança - Manual escolar - Estereótipo social.

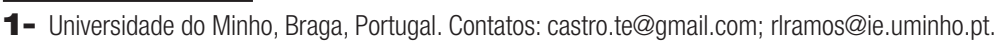

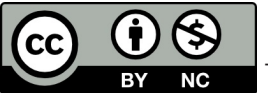




\title{
Social stereotypes in the voice of children: an analysis of school books of the Portuguese Basic Education
}

\begin{abstract}
The present study fits in the general field of Child Studies. It analyses a set of selected texts from school handbooks and textbooks used by the Portuguese Education System (4th grade of elementary school). It aims at revealing the representations that these texts make of children and childhood, through giving voice to children, as well as the way these representations are presented to the reading children, influencing their ways of being, thinking and acting. For that purpose, it grants special importance to linguistic materiality and to enunciation, within the framework of discourse analysis. It also takes contributions from the theories of enunciation, textual analysis, pragmatics, socio-discursive interactionism and sociology of childhood. This study concludes that children represented in these texts are portrayed as deprived of voice and power: they are consumers but not co-producers of culture. The child characters are depicted as submissive to the instituted powers and almost never express their opinion about the matters concerning them. In addition, they simply follow the rules and obey to those who have the power to enforce authority and punishments. These texts are mainly configured as texts of resignation, not of questioning.
\end{abstract}

\section{Keywords}

Discourse analysis - Child - School handbook - Social stereotype.

\section{Introdução}

Com este estudo pretende-se identificar as imagens que os textos dos manuais escolares $^{2}$ de Português utilizados em Portugal no $1^{\circ}$ Ciclo do Ensino Básico ${ }^{3}$ constroem das crianças e da infância, bem como os recursos linguísticos associados a tal construção. Acredita-se que essas imagens influenciam as perceções das crianças-leitoras e, consequentemente, as suas ações e as suas posturas perante os outros e perante si mesmas.

Utilizar-se-á uma abordagem teórica e metodológica pluridisciplinar einterdisciplinar, tendo como eixo orientador da investigação a centralidade da criança. 0 corpus de análise é constituído por textos dos manuais utilizados pela maioria dos alunos das escolas

2- A designação manual escolar, em Portugal, corresponde ao que, no Brasil, é referenciado como livro escolar. Trata-se do livro de apoio escolar com textos, exercícios, informação gramatical, etc., que propõe uma planificação e uma calendarização das atividades e que se subordina aos programas oficiais em vigor.

3- Corresponde às séries iniciais no Brasil. Em Portugal, o Ensino Básico encontra-se organizado em três ciclos: o primeiro dura quatro anos, 0 segundo, dois anos e o terceiro, três anos. Segue-se o Ensino Secundário (Ensino Médio, no Brasil), com a duração de três anos. 
portuguesas do $4^{\circ}$ ano de escolaridade. A análise do discurso, espaço de confluência de vários saberes, constitui a base científica adotada nesta investigação, uma vez que engloba os fundamentos teóricos e metodológicos mais adequados a esta pesquisa. Contudo, não se pretende apenas investigar os aspetos linguísticos, procurando-se também contributos de pesquisas realizadas em torno dos Estudos da Criança (ligados à educação). Assume-se que os manuais escolares são objetos de estudo relevantes, seja considerando o seu uso como instrumentos de apoio ao ensino-aprendizagem, seja considerando o seu papel social de veiculação de modos de configurar o mundo (CHOPPIN, 1992; CASTRO et al., 1999; DIONÍSIO, 2000; APPLE, 2002; CASTRO, 2008; RAMOS, 2009; CLAUDINO, 2011).

Consideram-se fundamentais alguns contributos que nos chegam da sociologia da infância, nomeadamente a afırmação segundo a qual, desde o seu nascimento, a criança se torna herdeira da cultura que alicerça a sociedade a que pertence e esta condicionará a sua forma de ser e de estar no mundo; mas que, por outro lado, não podemos considerar a criança apenas como assimiladora de cultura, pois ela interpreta e participa em sua construção (SARMENTO; PINTO, 1997; SARMENTO, 2000, 2004, 2005, 2007, 2011; RASMUSSEN, 2004; FERNANDES; VIDIGAL, 2005; RUBIO et al., 2014). A sociologia da infância tem vindo a defınir os conceitos de criança e infância tentando proporcionar um lugar pleno de direitos à criança, considerando-a como cidadão ativo e participativo na vida e nas decisões da sociedade. Para esses sociólogos, a criança não pode ser vista como um ser passivo, mas como indivíduo com capacidade para colaborar na vida da sociedade, assumindo determinados papéis e manifestando a sua opinião sobre os assuntos que dizem respeito à vida nessa mesma sociedade.

Quando pensamos em criança e infância, pensamos também em escola - instituição social concebida fundamentalmente para educar os indivíduos, principalmente as crianças. Desde a sua criação no século XVIII, a escola pública institucionalizou-se e generalizou-se, tendo o Estado assumido o papel de proteger e educar as crianças (que deixaram, assim, de se circunscrever ao espaço doméstico e de depender em exclusivo da proteção parental), atribuindo à escola a função de transmitir o saber socialmente válido e indispensável que serve de base a uma dada cultura. ${ }^{4}$ É por isso que a escola assume a sua função socializadora, dedicando-se à formação moral e cívica dos alunos, para além da instrução (ARIÈS, 1981; GIDDENS, 1997; PAIS, 1998; CORREIA, 2005). Mais ainda: para Sarmento (2011), a escola é um dos eixos estruturantes da definição da infância contemporânea, definidora das representações, das prescrições, das obrigações e das interdições configurantes das práticas e do estatuto próprios das crianças, integrantes do ofício da criança. Para o autor, a escola oferece à criança-aluno um estatuto e uma função: a de se deixar formatar, a de

[...] adquirir a cultura escolar - deixando de lado [...] a sua cultura de origem, quando incompatível com a cultura escolar, ou a cultura gerada e reproduzida nas relações com os seus pares: as culturas da infância - e ajustar-se à disciplina do corpo e da mente induzida pelas regras e pela hierarquia dos estabelecimentos de ensino que frequenta. (SARMENTO, 2011, p. 589).

4- Em Portugal, isto é particularmente válido no último século, após a instauração da República. 
Os textos constitutivos do corpus a analisar serão escrutinados na sua materialidade linguística, adotando, como foi referido, os fundamentos teóricos e metodológicos da análise do discurso $(\mathrm{AD})$. Esse ramo da linguística recebe contributos de várias áreas do saber, que se ocupam da análise e da descrição dos discursos produzidos por indivíduos devidamente contextualizados. Salientam-se entre os mais relevantes contributos os de áreas do saber como a pragmática linguística (AUSTIN, 1962; SEARLE, 1969; MAINGUENEAU, 1990, 1996; FONSECA, 1994): entendendo-se o mundo como construído no e pelo discurso, os textos são considerados instrumentos de construção desse mundo, pois só é possível conceber um ato discursivo se este visar a uma finalidade ilocucional (RAMOS, 2014). A AD assume o homem como ser social (FOUCAULT, 1969; VAN DIJK, 1985; BRONCKART, 1985, 2009; FONSECA, 1992; KERBRAT-ORECCHIONI, 1996) e analisa os textos/discursos baseando-se no uso efetivo da língua em contexto.

Acresce que os trabalhos de Adam (1990, 1992), realizados no âmbito da linguística textual, tornam-se basilares para a análise dos textos/discursos, tendo em conta que aqui estes são entendidos como unidades configuracionais heterogéneas e complexas, mas coerentes. Os textos/discursos configuram-se em planos de organização que se encontram em constante interação. São tessituras extremamente complexas, organizadas em torno de sequências prototípicas dominantes e estas em estruturas composicionais, convergindo para um significado global. No entanto, os textos não nascem do nada, do silêncio absoluto (BAKHTIN, 1992). As produções discursivas ancoram-se em discursos anteriores, preveem discursos subsequentes e inscrevem-se em determinadas conjunturas sociais, tornando incontornável a noção de polifonia ou heterogeneidade enunciativa - as marcas de outras vozes, inscritas no discurso através de estratégias linguísticas mais ou menos explícitas. Os textos decorrem de processos de modalização que se concretizam em reportórios interpretativos (POTTER; WETHERELL, 1987), selecionados pelo enunciador para facilitar a evocação de frames (FILLMORE, 1975) ou quadros conceituais convocados durante a leitura. Esse processo tem por base a enciclopédia de saberes do alocutário, construída ao longo de consecutivas leituras, bem como através das suas vivências individuais e sociais.

\section{Metodologia e corpus de análise}

Os textos em análise foram recortados dos seguintes manuais de Português do $4^{\circ}$ ano do $1^{\circ}$ Ciclo do Ensino Básico de Portugal:

Pasta Mágica - Língua Portuguesa $4 .^{\circ}$ ano (PEREIRA, 2006);

Amiguinhos - Lingua Portuguesa $4 .^{\circ}$ ano (ROCHA; LAGO; LINHARES, 2006);

Giroflé - Lingua Portuguesa $4 .{ }^{\circ}$ ano (MARQUES; SANTOS; GONÇALVES, 2006).

A escolha desses manuais teve por base informações facultadas pela Direção-Geral da Educação, segundo a qual foram os mais utilizados no $4^{\circ}$ ano do $1^{\circ}$ Ciclo do Ensino Básico, cobrindo um total de 54,35\% dos alunos matriculados no $4^{\circ}$ ano de escolaridade no ano letivo de 2010/2011, constituindo uma amostra representativa da totalidade dos 
manuais utilizados no país e permanecendo em utilização até ao final do ano letivo de 2012/2013. Foi escolhido o $4^{\circ}$ ano por constituir a última etapa do $1^{\circ}$ Ciclo do Ensino Básico e fundamental para todo o percurso educativo do indivíduo, com capacidade de repercutir as boas e más experiências por toda a vida. Por uma questão de distanciação e objetividade, foram analisados manuais que já não se encontram em uso nas escolas, mas considera-se que os resultados desta análise serão válidos e relevantes para a reflexão sobre as escolhas de manuais para o futuro. Uma breve reflexão, nas conclusões, integra considerações genéricas sobre livros atualmente em uso.

Por uma questão de economia e funcionalidade, neste texto apresentam-se sobretudo os resultados da análise, não cabendo aqui o desenvolvimento de todo o processo analítico micro e macrotextual. Este poderá ser encontrado, no essencial, em Castro (2014).

Para proceder à seleção dos textos que serviriam de suporte à presente investigação, utilizou-se como critério a construção linguística de imagens de crianças ou da infância, tendo sido selecionados os que constroem, apresentam ou convocam, de forma explícita ou implícita, imagens de crianças ou da infância concretizadas na presença de personagens infantis, de crianças como narradores ou sujeitos de enunciação, assim como a apresentação ou construção de mundos prototípicos da criança: brincadeiras, atitudes, relações, linguagem, cenários, etc. Desta forma, obteve-se um corpus global de 110 textos, que foram classificados conforme a tipologia textual definida pelo Dicionário terminológico, segundo o qual "os textos, para além das propriedades fundamentais da textualidade, apresentam estruturas verbais peculiares, semânticas e formais, e marcas pragmáticas que possibilitam a sua classificação em tipos ou géneros". ${ }^{5}$ Esse documento oficial, da responsabilidade do Ministério da Educação e Ciência português, é orientador das práticas letivas no Ensino Básico e Secundário.

Segundo Maingueneau (2005, p. 141), os textos são produzidos tendo em vista determinado público, sendo que

[...] a própria rede institucional desenha uma rede de difusão, as características de um público, indissociáveis do estatuto semântico que o discurso se atribui [...]. 0 "modo de difusão" vai de mãos dadas com o modo de consumo do discurso, isto é, com o que se "faz" dos textos, como eles são lidos, manipulados.

Neste sentido, os textos presentes nos manuais escolares são produto de uma dupla intencionalidade: a do autor original e a do autor do manual. Originalmente, o texto foi produzido com uma intencionalidade comunicativa e visando a determinado público, mas, numa segunda instância, o texto (ou parte desse texto) foi selecionado com uma intencionalidade comunicativa que pode ser (e é, muitas vezes) diferente da original. Também o público-alvo pode ser diferente, como é o caso de excertos de obras concebidas para leitores adultos e que são utilizados nos manuais escolares para serem estudados por crianças. Concorda-se aqui, pois, com Maingueneau (2005, p. 188) quando este afirma que, "mesmo quando se republicam textos, mesmo quando se produzem novos

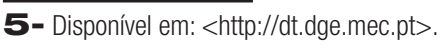


textos que parecem resultar da mesma competência discursiva, não se poderia falar dos mesmos discursos". Entendemos, portanto, que os textos presentes nos manuais escolares, ainda que possam ser apenas excertos, são sujeitos a processos de retextualização e recontextualização, transformando-se em novos textos (CASTR0, 2007), enformados por essa dupla intenção comunicativa.

0 manual escolar ocupa um lugar central no processo de ensino e aprendizagem (CHOPPIN, 1992) e é reprodutor do conhecimento entendido como socialmente válido, ao mesmo tempo em que funciona como aparelho de controlo social (APPLE, 2002). É esse o estatuto que o manual escolar assume para alunos, pais e (muitos) professores, o de detentor do saber inquestionável e socialmente válido. É por esse motivo que o manual de Português se torna tão relevante, uma vez que é através dele que o aluno vai contactar mais de perto com o modo escrito da sua língua, aprendendo a manipular os mecanismos linguísticos que lhe permitem utilizá-la não só para transmitir informações, mas também para eficazmente exercer influência e poder sobre os outros (CASTRO; RAMOS, 2014).

Como lembra Maingueneau (1997, p. 63), “[...] é preciso [...] não perder de vista que o termo 'escola' não é unívoco. Ele remete a um só tempo a uma instituição, a práticas, a lugares... à escola que se legitima ao enunciar - é tudo isto ao mesmo tempo". Logo, os manuais de Português são enformados por um enquadramento social que os reveste de enorme importância e os torna excelentes veículos de transmissão de valores, de ideologias e de modos de ser e estar na vida e na sociedade. Ora, essa transmissão de conhecimento e de valores é particularmente expressa, de forma mais ou menos explícita, nos textos que servem e tornam possíveis as finalidades educativa e comunicativa com que são escolhidos, criados ou recriados. Os textos dos manuais de Português são, portanto, aqui entendidos como importantes veículos na construção e na transmissão de cenários prototípicos de normalidade, capazes de criar imagens da infância na sociedade, influenciando as formas de pensar e agir dos potenciais utilizadores (CASTRO, 2014).

\section{A voz das crianças nos textos}

$\mathrm{Na}$ perspetiva da sociologia da infância, não basta que os adultos zelem pelos direitos da criança fazendo proclamações de princípios gerais e vagas, ou as defendam de eventuais riscos. É também importante que eles reconheçam efetivamente o direito de as crianças terem voz ativa na sociedade para nela intervirem, assumindo uma cidadania participativa e exercendo influência sobre as decisões que os adultos tomam sobre os mais variados assuntos.

Assumindo (como foi referido) que os manuais escolares incorporam a virtualidade de construírem e difundirem imagens poderosas dos estados de coisas normais na sociedade, procurou-se identificar as marcas linguísticas que permitem reconhecer a voz das crianças nos textos desses livros. Subjaz a essa tarefa a aceitação do construtivismo linguístico, pois é através da língua que o mundo se constrói linguisticamente e que as ideias e os valores se edificam. É também através da língua que tais ideias e valores se 
transmitem e influenciam a forma de pensar e agir dos outros, pois é através da linguagem que a consciência do homem é modelada.

A voz das crianças pode ser inscrita nos textos de diversas formas. Há casos em que o sujeito da enunciação é uma criança, outros em que aparecem crianças representadas como personagens principais e/ou personagens secundárias, e ainda outros textos que elegem como alocutário, mais ou menos explícito, a criança-leitora.

\section{A criança como sujeito da enunciação}

Utilizar a voz da criança como sujeito da enunciação é uma estratégia linguística que garante a aproximação do texto ao leitor eleito, pois trata-se de colocar o discurso a realizar-se entre pares, potenciando a adesão do leitor às ideias transmitidas. Verifica-se que o discurso desses textos reflete grande parte do discurso dos adultos para as crianças, estratégia de camuflagem do que é transmitido e da intenção com que é dito. Para conseguir esse efeito nos leitores, o enunciador serve-se de várias estratégias linguísticas. Há textos enformados por características da máxima educativa, ou pedagógica, que se apresentam como prontos a serem memorizados e interiorizados, com o intuito de condicionarem as ações dos leitores eleitos. 0 uso da primeira pessoa (tenho de fazer... / devo fazer...) oculta o caráter diretivo dos textos e configura o seu conteúdo como uma adoção consciente de uma forma de ser e de agir por parte do enunciador, influenciando o comportamento da criança-leitora. Uma outra estratégia utilizada pelo enunciador é recorrer à máxima que convoca o valor de verdade incontestável do saber popular, usando uma voz comum aceite por toda a sociedade, realizando uma forma de modalidade epistémica. A par dessa modalização dos discursos, encontramos formas de modalidade deôntica, frequentemente inscritas no semantismo do verbo dever, que enforma os textos de valores e normas a seguir pelos leitores eleitos. Mesmo quando é a voz de uma criança que enuncia, é a voz do adulto que se ouve, que se camufla na voz da criança. Esse eco que se ouve proveniente de outros enunciados atesta a característica polifónica dos discursos (BAKHTIN, 1992) e contribuiu para esclarecer os posicionamentos do enunciador perante o conteúdo temático (BRONCKART, 2009).

Em alguns textos, a voz infantil mostra uma certa discordância para com algumas das ideias dos adultos. Só que essa discordância não passa de uma mera estratégia para ocultar a verdadeira opinião do enunciador, pois, no final do texto, prevalecem sempre as ideias do adulto e, algumas vezes, é a própria criança quem lhe dá razão. No final dos textos, fica sempre confirmado que o adulto tem razão e a criança é sempre caracterizada como ser inexperiente, que precisa de ajuda e de apoio constantes. No entanto, ao demonstrar coragem para contestar as ideias do adulto, o enunciador conquista a simpatia da criança-leitora, o que facilita a tarefa de orientar o discurso no sentido de colocar a criança em consonância de ideias com o adulto.

Encontramos, ainda, uma outra estratégia utilizada pelo enunciador para legitimar o poder dos adultos em relação às crianças. Trata-se de uma estratégia bastante dissimulada, na medida em que leva o leitor a pensar que se legitimam e desculpabilizam os comportamentos desviantes da criança-personagem, atribuindo culpas, supostamente, 
aos adultos por estes serem tão rigorosos com o estabelecimento e o cumprimento de regras. Só que os textos acabam por mostrar crianças que se veem obrigadas a mentir e a fingir para evitar castigos e mostrar obediência ao adulto, normalizando os manuais a ideia de que o melhor caminho é sempre a obediência.

Do ponto de vista pragmático, esses textos visam a um objetivo ilocutório de convencer as crianças de que o adulto tem sempre razão. Estabelecem-se as posições de poder numa forma de endoutrinação ou de aculturação, bem como de manutenção do poder instituído. Tais textos são, portanto, promotores de aceitação, acomodação e sujeição ao poder.

É frequente encontrarmos discursos introduzidos pela fórmula quando eu for grande, bem conhecida das crianças-leitoras, apresentando uma dimensão prospetiva e colocando a criança perante uma visão do futuro que a espera. Essa dimensão sai reforçada por ser a voz de uma criança que enuncia não só os seus desejos e sonhos, mas também os de todas as outras crianças. A criança é frequentemente configurada como ser em devir - quando for grande, irá fazer muitas coisas -, subentendendo-se que, por enquanto, nada ou muito pouco faz, configurando-se a infância como um tempo de espera e a criança como ser incompleto, um ser a quem falta alguma coisa para se realizar plenamente.

As crianças dos textos demonstram emoções/sentimentos através do que dizem ou das suas atitudes. Encontramos duas crianças indignadas com a falta de confiança demonstrada pelo adulto, mas pouco ou nada fazem para reverter a situação, e uma criança que se espanta com a liberdade que reconhece àquelas que brincam na rua e sente desejo de conquistar essa liberdade para si, sentindo necessidade de mentir aos adultos para brincar na rua também. Há, ainda, crianças que, para além de estarem felizes, parecem refletir sobre esse estado, num claro exercício de autoanálise muito mais próprio de comportamentos adultos do que de crianças, comprovando-se o uso da voz infantil somente como veículo para dar voz às ideias dos adultos.

Há crianças que sonham e demonstram confiança ao acreditarem na realização desses sonhos. Trata-se principalmente de sonhos que configuram a vida adulta como um estado em que se pode fazer tudo, em que se tem poder. Configura-se a definição do indivíduo pela profissão que exerce e não pelo que é como pessoa, o que reflete uma forma de construir a sociedade e de nela cada um se inserir.

Em nenhum desses textos encontramos uma criança manifestamente infeliz. No entanto, a infância configura-se nos textos como uma fase da vida dos indivíduos desprovida de poder, em que pouco se pode fazer, a não ser esperar que se cresça para poder ser tudo. Desta forma, cria-se da infância uma imagem de período de estagnação e de espera por algo que inevitavelmente ocorrerá no futuro, não se apresentando à criança outra solução que não seja esperar e confiar no que lhe dizem sobre ser adulto e os seus benefícios.

Nos textos escritos na primeira pessoa, a imagem que se apresenta das crianças é a de indivíduos socialmente imaturos (SARMENTO, 2007) e da infância como tempo de espera pela vida adulta. Ao atribuir-se todo o poder aos adultos, configuram-se as crianças como indivíduos sem voz e sem autoridade para intervir na sociedade, enformando-se a infância de uma certa negatividade (SARMENTO, 2005). Esta é uma forma de garantir os poderes instituídos na e pela sociedade, provavelmente mais própria de Estados totalitários do que de democracias participativas e progressistas. 


\section{A criança como personagem principal}

Quando temos uma criança que assume o papel de protagonista, ela também assume um papel preponderante na transmissão de ideias, valores e (pre)conceitos, mais facilmente influenciando a criança-leitora. Não nos esqueçamos de que estamos perante textos predominantemente oriundos da literatura infantil, que possui um forte poder de aculturar e normalizar, potenciado pela sua inclusão nos manuais escolares.

Também nesses textos encontramos crianças que apresentam discursos muito semelhantes aos dos adultos. Por vezes, a criança recupera (evoca) um discurso anterior de outro enunciador, o professor. Nesses casos, o poder persuasivo do texto é triplicado: diz o professor, diz a criança e diz o manual escolar. Nunca são textos cujo objetivo ilocutório seja o questionamento ou a crítica, mas a conformação e a aceitação por parte das crianças do que pensam, dizem e fazem os adultos, confirmando-se e normalizando-se as relações hierárquicas e de poder instituídas pela sociedade.

Nesses textos, o tema mais abordado é a brincadeira, mas esta assume o mesmo estatuto de outros temas e parece que as crianças muito pouco têm a dizer sobre esse assunto específico. 0 quadro de brincadeira é apenas um cenário para falar de outras coisas - a poluição, a solidariedade, etc. -, apresentando-se os textos enformados do macro-objetivo ilocutório de moralizar a criança-leitora. Nesse conjunto de textos encontra-se o único de todo o corpus onde se retratam relações não harmoniosas entre crianças. No entanto, a referência a essas relações apenas serve de ponto de partida para se moralizar o leitor, procurando incutir-lhe valores morais de solidariedade.

Alguns dos comportamentos dessas crianças são semelhantes aos dos adultos e, por vezes, chegam até a demonstrar capacidade de afastamento e autorreflexão em relação à sua vida, o que as configura mais perto dos adultos do que das crianças. Apesar disso, quando não cumprem o que os adultos estabeleceram, recebem castigo. A diferença entre adulto e criança volta a afırmar-se nas relações de poder.

Estamos perante crianças que demonstram sentido de responsabilidade, algumas vezes assumido pela condição social que ocupam nos textos. Portanto, a responsabilidade aparece intimamente ligada à condição social, mas também ao poder. Mas a responsabilidade também é mostrada a outros níveis, por exemplo, nas atitudes que crianças tomam para com os outros: salvar alguém, resolver problemas, ensinar algo, realizar os trabalhos da escola, ajudar os adultos e não os atrapalhar. A responsabilidade atribuída a essas crianças está muito relacionada com os adultos e com o que eles esperam delas, por isso encontramos crianças que demonstram responsabilidade ao tentarem não atrapalhar as tarefas dos adultos. 0 frame criança incompetente é desenhado não só pelas atitudes de adultos e crianças, mas também pela modalização operada no material verbal que faz ressaltar a competência dos adultos perante a incompetência das crianças.

Essas crianças, assim como as que assumem o papel de narrador, nunca se revoltam, mesmo não concordando com os adultos, e acabam sempre por se revelar obedientes. É verdade que não se pode esperar que as crianças dos textos liderem revoluções, mas estranha-se o facto de nunca se questionarem sobre a sua condição e de, mesmo quando pontualmente discordam do adulto, acabarem sempre por lhe dar razão. 
Encontramos também representados sentimentos de bondade, revelados nas atitudes que as crianças têm para com os outros. Para fazer notar essa bondade, o enunciador encontra recursos linguísticos, como a utilização de nome próprio para referir a criança bondosa e outro menos definido para se referir às outras personagens. Mas também pode apagar por completo o nome da criança e tornar apenas evidentes as suas qualidades: não importa quem é, mas tem uma bondade extrema. Estas e outras são estratégias que permitem elevar a personagem principal e evidenciar as suas qualidades que poderão ser imitadas pelas crianças-leitoras.

\section{A criança como personagem secundária}

As personagens secundárias desempenham um papel menos relevante nos textos e, por essa razão, a sua voz é ainda menos ouvida. À semelhança do que acontece com as personagens principais, também as crianças que vestem a pele de personagens secundárias reproduzem as ideias próprias de adultos que desempenham funções pedagógicas e/ou funções educativas. Através da voz das personagens secundárias, idealiza-se a vida no campo em detrimento da vida na cidade, sem nunca se falar também nas desvantagens que essa opção de vida comporta.

Apenas existe um texto em que os discursos das crianças mostram discordância para com o discurso do adulto (professor). No entanto, como evidencia a materialidade linguística, os alunos, mesmo não concordando com o professor, sentem-se compelidos a obedecer-lhe. Mas o enunciador modaliza o discurso por forma a torná-lo mais credível aos olhos do leitor, tratando também de salvar a face das crianças. Trata-se de uma forma de conservar o poder instituído e manter a ordem social.

Também essas crianças se abstêm de se manifestarem sobre as brincadeiras, apesar de participarem delas. Tudo nesses textos aparece predefinido, como se as brincadeiras não fossem planeadas pelas próprias crianças, mas por outro qualquer indivíduo externo à brincadeira. Um outro dado que importa sublinhar é que as atividades relacionadas com as brincadeiras descritas nos textos parecem profundamente anacrónicas, uma vez que nunca se faz referência a brinquedos ligados às novas tecnologias, por exemplo. São, muito provavelmente, as brincadeiras que os autores dos textos faziam quando eram crianças, filtradas pelas suas memórias da infância.

Essas crianças aparecem também conformadas com a sua situação e demonstram uma total ausência de voz sobre os assuntos que lhe dizem respeito. Continuamos a ter crianças solidárias com os outros e os discursos são orientados no sentido de evidenciar os mais desfavorecidos, contribuindo para que o leitor desenvolva sentimentos de solidariedade. Para conseguir esse efeito, o enunciador modaliza o discurso, nomeadamente através do recurso à adjetivação, que constrói a imagem dos desfavorecidos e convoca a voz do senso comum para corroborar aquilo que diz.

Nesse conjunto de textos encontramos dois em que as crianças demonstram algum desprezo em relação aos outros. Tais textos promovem a aproximação entre as crianças dos textos e as crianças reais e deixam implícito que aquele não é um bom sentimento, procurando sensibilizar a criança-leitora para que adote comportamentos inversos aos 
apresentados nesses casos. Estamos perante uma inversão das situações: não se apresenta o que se deve, mas antes o que não se deve fazer.

\section{A criança eleita como alocutário explícito}

Alguns textos elegem, de forma mais ou menos explícita, a criança-leitora como alocutário, dirigindo-se-lhe o sujeito da enunciação diretamente, fazendo parecer que o texto foi escrito propositadamente para ela. Nesse caso, o enunciador (quase) estabelece um diálogo com a criança-leitora e, embora ela não lhe possa responder, essa resposta ficará inscrita nos comportamentos que irá adotar, influenciada pelo que lhe dizem os textos. Para levar a cabo tal tarefa, nada melhor do que optar por textos instrucionais, aparentemente os ideais para atingir o objetivo ilocutório de fazer-fazer.

Esses textos realizam macroatos ilocutórios diretivos, com a clara intenção de levar a criança a fazer alguma coisa ou a modelar os seus comportamentos. No limite, visam à manutenção de uma sociedade organizada e pacífica e, para isso, difundem normas de conduta e valores que essa sociedade considera essenciais, tal como acontece em qualquer época. Os títulos são os primeiros recursos que o enunciador convoca, pois logo anunciam normas de boa educação nas mais variadas situações sociais, bem como normas de segurança que visam ao assumir de comportamentos responsáveis ("Ser bem-educado... na Escola!" ou "0 silêncio é de ouro!... A Natureza também!”, por exemplo).

Tais textos cumprem uma múltipla função pragmática: fazer-saber, fazer-fazer e saber-ser. É nas últimas dimensões que está a maior e mais influente força ilocutória. 0 enunciador utiliza várias estratégias que permanecem inscritas na materialidade linguística dos textos: utilização de verbos no imperativo e expressões com valor modal de dever, a forma como familiarmente trata por $t u$ o leitor, assim como expressões que ostentam o valor modal de demonstrar as vantagens que o leitor tem ao respeitar as regras sociais, etc.

\section{Conclusões}

Suportados nos pressupostos teóricos e metodológicos identificados, selecionaram-se os textos dos manuais escolares de Português para elencar as imagens das crianças e da infância que neles se constroem, convictos de que estas, potenciadas pelo estatuto que os manuais assumem na sociedade, influenciam a forma de pensar, de ser e de agir das crianças-leitoras, bem como normalizam essas mesmas imagens, que não são mais do que constructos sociais e ideológicos. Os textos dos manuais são enformados por dois enfoques distintos: o do autor do texto-origem e o do autor do manual. Embora os pais sejam os primeiros educadores, a escola sempre assumiu o papel de educadora de massas, educadora de uma consciência coletiva que se deseja harmoniosa e consistente, para garantir unidade e estabilidade social. No entanto, o autor do texto/manual não pode deixar de inscrever nele também as suas crenças e os seus valores pessoais, e o texto/manual assume-se como modelador de mentes e de condutas.

A voz das crianças faz-se ouvir nos textos através da voz das personagens infantis que os povoam ou através da voz do narrador, se este for concretizado numa voz infantil. 
Enunciar através da voz de uma criança aproxima locutor de alocutário e o mesmo acontece quando o destinatário dos textos é explicitamente a criança, utilizando-se o tratamento familiar $t u$.

É indiscutível que as personagens principais assumem um maior protagonismo nos textos, mas, apesar disso, a (efetiva) voz das crianças é muito pouco inscrita na materialidade linguística dos textos. As crianças dos textos reproduzem ideias tipicamente de adultos, por vezes elaborando raciocínios tão sofisticados que se tornam improváveis nas suas vozes. Na verdade, também encontramos discursos infantis que, aparentemente, e num determinado ponto, discordam das ideias dos adultos, mas esta é uma discordância fictícia e passageira, tratando-se de afirmar a concordância/submissão logo a seguir. Algumas vezes, o comportamento conciliador demonstrado pelas crianças é motivado pelo receio de uma possível punição, decidida e aplicada pelos adultos.

As atividades dessas crianças relacionam-se bastante com a brincadeira e o jogo, mas são referidas de forma breve e pouco evidenciada e quase nunca se torna presente a voz das crianças em discussões sobre o assunto. Raramente as crianças falam sobre a escolha, os parceiros ou o local da brincadeira. Tudo parece predefinido antes dos textos e sem participação dos protagonistas.

As crianças dos textos apresentam-se conformadas com a sua situação pessoal e social, mesmo se adversa, e não tomam atitudes para modificar essa situação. São crianças exemplares que nunca protestam, apesar de, em alguns casos, passarem necessidades básicas. São crianças bem comportadas, sempre dispostas a ajudar os outros (os adultos, principalmente), embora poucas vezes essa ajuda seja realizada com sucesso. Aos olhos dos adultos, as crianças atrapalham mais do que ajudam. São crianças sem poder, pois este está completamente concentrado nos adultos, e que assumem um papel de submissão aos poderes instituídos. Tal observação é compatível com o que afirmam Müller e Nunes (2014, p. 653) acerca dos próprios estudos sociológicos tradicionais que assumem a infância como objeto: estes tratam essa categoria "como fase transitória em direção à maturidade, sem autonomia frente ao mundo adulto e submetida a processos de socialização que as preparariam para a vida adulta". Os textos dos manuais refletem essa visão dos estados de coisas; neles se evoca o frame de infância como tempo de espera entre o não-saber-fazer-nada e o saber-fazer-tudo, entre o não-saber-nada e o saber-tudo, entre o não-ter-poder-algum e o ter-todo-o-poder sobre si e sobre os outros.

Apesar de serem crianças sem opinião (ou por isso mesmo), vivem felizes até nos cenários mais adversos e nunca se questionam ou questionam o poder instituído. Tudo o que encontramos nos textos em relação à voz das crianças contraria as ideias defendidas pelos sociólogos da infância que reclamam o direito das crianças a uma participação ativa na sociedade, não só como consumidoras de cultura, mas também como coprodutoras. É que a cultura não é um mero acumular de conhecimentos, é algo dinâmico (SARMENTO, 2000), no sentido em que todo o indivíduo interpreta e age sobre a cultura. Apesar disso, é o que fica inscrito nos textos e que reflete o que a sociedade e o poder instituído esperam das crianças que vai influenciar e moldar a criança-leitora.

Os manuais em estudo estiveram em vigor até ao final do ano letivo 2012/2013, findo o qual novos manuais entraram nas escolas portuguesas, verificando-se uma evolução na 
seleção e na apresentação dos textos nos manuais de Português: os excertos textuais são mais longos, respeitam mais os originais, contêm referências bibliográficas que permitem (tentar) encontrar os textos originais e nota-se um esforço por incluir diferentes tipologias textuais. No entanto, mesmo uma análise relativamente elementar e geral mostra que os textos parecem continuar norteados pela dicotomia certo/errado, orientando a criança para uma forma de ser e estar estereotipada, não a incentivando a pensar por si - trata-se mais de textos de conformação do que de questionamento. São textos que não colaboram na construção de cidadãos conscientes, críticos e interventivos, apenas funcionam como formatadores de determinado modo de estar na vida, parecendo visar unicamente à reprodução e à estabilidade sociais.

\section{Referências}

ADAM, Jean-Michel. Éléments de linguistique textuelle: théorie et pratique de l'analyse textuelle. Liège: Mardaga, 1990.

ADAM, Jean-Michel. Les textes: types et prototypes. Liège: Mardaga, 1992.

APPLE, Michael. Manuais escolares e trabalho docente: uma economia política de relações de classe e de género na educação. Lisboa: Plátano, 2002.

ARIÈS, Philippe. História social da criança e da família. Rio de Janeiro: Zahar, 1981.

AUSTIN, John Langshaw. How to do things with words. Oxford: Clarendon, 1962.

BAKHTIN, Mikhail. Estética da criação verbal. São Paulo: Martins Fontes, 1992.

BRONCKART, Jean-Paul. Le fonctionnement des discours. Paris: Delachaux \& Niestlé, 1985.

BRONCKART, Jean-Paul. Atividades de linguagem, textos e discursos: por um interacionismo sociodiscursivo. São Paulo: Educ, 2009.

CASTRO, Teresa. Representações da infância no manual escolar: uma abordagem linguística dos textos de manuais do $4 .^{\circ}$ ano de Português. 2014. Tese (Doutoramento) - Universidade do Minho, Braga, 2014.

CASTRO, Teresa. Texto e fragmento textual: processos de re(con)textualização. 2007. Tese (Mestrado) Universidade do Minho, Braga, 2007.

CASTR0, Teresa. Texto e fragmento textual: processos de re(con)textualização. Diacrítica, Braga, v. 22, n. 1, p. 157-184, 2008.

CASTRO, Rui Vieira et al. (Org.). Manuais escolares: estatuto, funções, história. Braga: Centro de Estudos em Educação e Psicologia. Instituto de Educação e Psicologia da Universidade do Minho, 1999. 
CASTRO, Teresa; RAMOS, Rui. Representações da infância no manual escolar em Portugal. Revista Vozes dos Vales, Diamantina, v. 3, n. 6, p. 1-32, 2014.

CHOPPIN, Alain. Les manuels scolaires: histoire et actualité. Paris: Hachette, 1992.

CLAUDINO, Sérgio. Os manuais escolares da $1^{\text {a }}$ República à actualidade: os insubmissos. In: DUARTE, José Bernardino (Org.). Manuais escolares: mudanças nos discursos e nas práticas. Lisboa: Edições Universitárias Lusófonas, 2011. p. 73-95.

CORREIA, António Carlos Luz. A normalidade imaginada: a fabricação da anormalidade escolar através do processo de implementação da escolaridade universal e obrigatória, na viragem do século xix para o século XX. In: FERNANDES, Rogério; VIDIGAL, Luís (Coord.). Infantia et pueritia: introdução à história da infância em Portugal. Santarém: Escola Superior de Educação de Santarém, 2005. p. 192-210.

DIONÍSIO, Maria Lourdes Trindade. A construção escolar de comunidades de leitores. Coimbra: Almedina, 2000.

FERNANDES, Rogério; VIDIGAL, Luís (Coord.). Infantia et pueritia: introdução à história da infância em Portugal. Santarém: Escola Superior de Educação de Santarém, 2005.

FILLMORE, Charles. An alternative to checklist theories of meaning. In: ANNUAL MEETING OF THE BERKELEY LINGUISTIC SOCIETY, 1., 1975, Berkeley. Proceedings... Berkeley: [s. n.], 1975. p. 123-131.

FONSECA, Joaquim. Linguística e texto/discurso: teoria, descrição aplicação. Lisboa: ICALP, 1992.

FONSECA, Joaquim. Pragmática linguística, introdução, teoria e descrição do português. Porto: Porto Editora, 1994. (Linguística; n. 5).

FOUCAULT, Michel. L’archéologie du savoir. Paris: Gallimard, 1969.

GIDDENS, Anthony. Sociologia. Lisboa: Fundação Calouste Gulbenkian, 1997.

KERBRAT-ORECCHIONI, Catherine. La conversation. Paris: Seuil, 1996.

MAINGUENEAU, Dominique. Pragmatique pour le discours littéraire. Paris: Bordas, 1990.

MAINGUENEAU, Dominique. Aborder la linguistique. Paris: Seuil, 1996.

MAINGUENEAU, Dominique. Gênese dos discursos. Curitiba: Criar, 2005.

MAINGUENEAU, Dominique. Novas tendências em análise do discurso. Campinas: Pontes, 1997.

MARQUES, Maria José; SANTOS, Maria Ascensão dos; GONÇALVES, Armando. Giroflé: língua portuguesa 4. ${ }^{\circ}$ ano. Lisboa: Santillana-Constância, 2006. 
MÜLLER, Fernanda; NUNES, Brasilmar Ferreira. Apresentação. Educação \& Sociedade, Campinas, v. 35, n. 128, p. 651-658, jul./set. 2014. Disponível em: <http://www.scielo.br/pdf/es/v35n128/0101-7330es-35-128-00651.pdf>. Acesso em: 15 jan. 2016.

PAIS, José Machado (Coord.). Gerações e valores na sociedade portuguesa contemporânea. Lisboa: Instituto de Ciências Sociais da Universidade de Lisboa, 1998.

PEREIRA, Cláudia et al. Pasta mágica: língua portuguesa 4. ${ }^{\circ}$ ano. Porto: Areal, 2006.

POTTER, Jonathan; WETHERELL, Margaret. Discourse and social psychology: beyond attitudes and behaviour. London: Sage, 1987.

RAMOS, Rui. Análise linguística do discurso: enunciação, modalização, reificação. In: BURLAMAQUE, Fabiane Verardi et al. (Org.). Das práticas do ler e escrever ao universo das linguagens, códigos e tecnologias. Porto Alegre: CirKula, 2014. p. 191-221.

RAMOS, Rui. 0 discurso do ambiente na imprensa e na escola: uma abordagem linguística. Lisboa: Fundação Calouste Gulbenkian: Fundação para a Ciência e a Tecnologia, 2009.

RASMUSSEN, Kim. Places for children: children's places. Childhood, v. 11, n. 2, p. 155-173, 2004. Disponível em: <http://chd.sagepub.com/content/11/2/155.full.pdf+html>. Acesso em: 17 jul. 2012.

ROCHA, Alberta; LAGO, Carla; LINHARES, Manuel. Amiguinhos: língua portuguesa 4. ${ }^{\circ}$ ano. Lisboa: Texto, 2006.

RUBIO, Pedro et al. ENCUENTRO DE LA CIUDAD DE LOS NIÑOS, 8., 2014, Madrid. Libro del 8. encuentro de la ciudad de los niños: infancia y ciudadanía. Madrid: Acción Educativa, 2014.

SARMENTO, Manuel Jacinto. A reinvenção do ofício de criança e de aluno. Atos de Pesquisa em Educação, Blumenau, v. 6, n. 3, p. 581-602, 2011.

SARMENTO, Manuel Jacinto. As culturas da infância nas encruzilhadas da segunda modernidade. In: SARMENTO, Manuel Jacinto; CERISARA, Ana Beatriz (Coord.). Crianças e miúdos: perspectivas sociopedagógicas da infância e educação. Porto: Asa, 2004. p. 9-34.

SARMENTO, Manuel Jacinto. Gerações e alteridade: interrogações a partir da sociologia da infância. Educação \& Sociedade, Campinas, v. 26, n. 91, p. 361-378, 2005.

SARMENTO, Manuel Jacinto. Lógicas de acção nas escolas. Lisboa: Instituto de Inovação Educacional do Ministério da Educação, 2000.

SARMENTO, Manuel Jacinto. Visibilidade social e estudo da infância. In: VASCONCELLOS, Vera Maria Ramos; SARMENTO, Manuel Jacinto (Org.). Infância (in)visível. Petrópolis: Vozes, 2007. p. 25-49. 
SARMENTO, Manuel Jacinto; PINTO, Manuel. As crianças e a infância: definindo conceitos, delimitando o campo. In: PINTO, Manuel; SARMENTO, Manuel Jacinto (Coord.). As crianças: contextos e identidades. Braga: Universidade do Minho, 1997. p. 7-30.

SEARLE, John. Speech acts: an essay in the philosophy of language. Cambridge: Cambridge University Press, 1969.

VAN DIJK, Teun Adrianus (éd.). Handbook of discourse analysis. 4 v. London: Academic Press, 1985.

Recebido em: 09.02.2017

Aprovado em: 23.05.2017

Teresa da Conceição Mendes de Castro é doutora em Estudos da Criança, investigadora colaboradora do Centro de Investigação em Estudos da Criança da Universidade do Minho (Portugal) e professora do $1^{\circ}$ Ciclo do Ensino Básico. Colaborou em equipas de avaliação e certificação de manuais escolares de Português e tem vindo a colaborar na elaboraçã̃o de manuais escolares.

Rui Manuel do Nascimento Lima Ramos é doutor em Linguística, professor do Instituto de Educação e pesquisador do Centro de Investigação em Estudos da Criança da Universidade do Minho (Portugal). Intervém ao nível da graduação e da pós-graduação e tem experiência de cooperação internacional. 